\title{
Analysis of tuberculosis treatment outcomes in the European Union and European Economic Area: efforts needed towards optimal case management and control
}

D Manissero (davide.manissero@ecdc.europa.eu) ${ }^{1}$, V Hollo² ${ }^{2}$ E Huitric ${ }^{1}$, C Ködmö̈n $^{2}$, A Amato-Gauci³

1. Scientific Advice Unit, Tuberculosis Programme, European Centre for Disease Prevention and Control, Stockholm, Sweden

2. Surveillance Unit, Tuberculosis Programme, European Centre for Disease Prevention and Control, Stockholm, Sweden

3. Surveillance Unit, European Centre for Disease Prevention and Control, Stockholm, Sweden

Citation style for this article: Manissero D, Hollo V, Huitric E, Ködmön C, Amato-Gauci A. Analysis of tuberculosis treatment outcomes in the European Union and European Economic Area: efforts needed towards optimal case management and control. Euro Surveill. 2010;15(11):pii=19514. Available online: http://www. eurosurveillance.org/ViewArticle.aspx?Articleld=19514

An analysis of surveillance data was performed to assess treatment outcomes of patients belonging to selected calendar year cohorts. Twenty-two countries in the European Union (EU) and European Economic Area (EEA) reported treatment outcome monitoring data for culture-confirmed pulmonary tuberculosis (TB) cases reported in 2007. The overall treatment success rate was $73.8 \%$ for all culture-confirmed pulmonary cases and $79.5 \%$ for new culture-confirmed pulmonary cases. For the cohort of new culture-confirmed TB cases, only three countries achieved the target of $85 \%$ success rate. This underachievement appears to be a result of relative high defaulting and unknown outcome information. Case fatality remains high particularly among cases of national origin. This factor appears attributable to advanced age of the national cohort. Treatment outcomes for multidrugresistant tuberculosis were reported by 15 countries, with a range of $19.8 \%$ to $100 \%$ treatment success at 24 months. The data underline the urgent need for strengthening treatment outcome monitoring in the EU and EEA in order to ensure an effective programme implementation and case management that will ultimately contribute to TB elimination.

\section{Background}

Tuberculosis (TB) remains a global emergency with estimates of 1.8 millions deaths worldwide in 2008 and over nine million cases. In 2008, the estimated global incidence rate fell to 139 cases per 100,000 population after reaching its peak in 2004 at 143 per 100,000. However, this decline was not homogeneous throughout the World Health Organization (WHO) regions, with Europe failing to record a substantial decline, but rather appearing to have reached a stabilisation of rates [1].

The 30 Member States of the European Union (EU) and European Economic Area (EEA) present a peculiar and highly heterogeneous situation in terms of TB epidemiology and control. Three broad epidemiological areas are distinguished within the borders of the EU/EEA: low incidence countries (below 20 notified cases per
100,000 population) with cases aggregating in vulnerable populations and only occasional increased notification rates; countries with moderate-to-high, but declining notification rates and with a low proportion of multidrug-resistant (MDR) TB; and finally, countries with relatively high notification rates (over 100 notified cases per 100,000) and high levels of MDR TB, but again with declining overall TB rates [2-4].

Attention to TB control in the EU and EEA has been raised in recent years through a number of initiatives, including the launching of a Framework Action Plan to Fight Tuberculosis in the EU [5]. Among the key issues underlined in the Action Plan is the need to achieve and sustain acceptable levels of treatment success among all TB patients.

Treatment success measured by a standardised process of treatment outcome monitoring (TOM) is one of the pillars of TB control and, along with case detection, is recognised as a key programmatic output. It is against this rationale that a World Health Assembly (WHA) resolution was passed in 1991, adopting two targets for global TB control: to detect at least $70 \%$ of new infectious cases and to cure at least $85 \%$ of those detected. These targets were linked to the Millennium Development Goals, and the Stop TB Partnership set the year 2005 as the deadline for achievement [6-8].

Globally, the treatment success rate has exceeded the $85 \%$ target for the first time in 2008 since the target was set in 1991, with a percentage of $87 \%$ for patients starting treatment in 2007. Furthermore, treatment success rates were maintained or improved between 2006 and 2007 in all WHO regions with the exception of the European Region which recorded the lowest success rate globally at $67 \%$ [1].

The importance of strengthening treatment outcome monitoring in Europe has long been recognised. A statement put forward by the WHO and the International Union against Tuberculosis and Lung 
Disease underlined in 1998 the need for standardisation and evaluation of treatment results for TB patients in the WHO European region, including those in low and intermediate incidence countries [9].

In this study we aimed to analyse treatment outcomes and progress towards the targets specifically for the EU/EEA region as a whole and its Member States separately.

Since 1 January 2008, the European Centre for Disease Prevention and Control (ECDC) and the WHO Regional Office for Europe have jointly coordinated the TB surveillance in Europe. Designated national surveillance institutions or individuals are responsible for providing the data, which is reported to a central joint database. Furthermore, historical data are available from the former EuroTB project for TB surveillance activities in Europe from 1996 to 2007. These data represent a valuable source for an in-depth analysis of treatment outcome monitoring and were used in our study.

\section{Methods}

A descriptive analysis of surveillance data was performed to assess treatment outcomes of patients belonging to selected calendar year treatment cohorts.
Data were extracted from The European Surveillance System (TESSy) and from the former EuroTB historical database for the 30 EU and EEA countries reporting data to the ECDC. Since the reporting year 2002, outcome data are collected for all individual cases by submission of an individual dataset for the 12 months before the year for which notification data are reported to TESSy, and since 2008 also for MDR treatment outcome for cases reported 24 months before the year for which notification data are reported to TESSy. The cases eligible for outcome analysis (cohorts) include all the culture-confirmed pulmonary TB cases notified in the calendar year of interest, after exclusion of cases with final diagnosis other than TB.

Country-specific data were extracted for 2007 for both new and retreatment laboratory-confirmed pulmonary TB cases for the analysis of 12 months of treatment outcome data. For 2006, country-specific data were extracted for laboratory-confirmed MDR TB cases (combined new and retreatment) for the analysis of 24 months of treatment outcome data. Aggregated EU/ EEA data were extracted for the period 2003 to 2007 for trend analysis of treatment outcome for new, retreatment and combined laboratory-confirmed pulmonary

\section{FIGURE 1}

Treatment outcome of laboratory-confirmed pulmonary cases, EU/EEA countries ${ }^{1} 2003-2007$

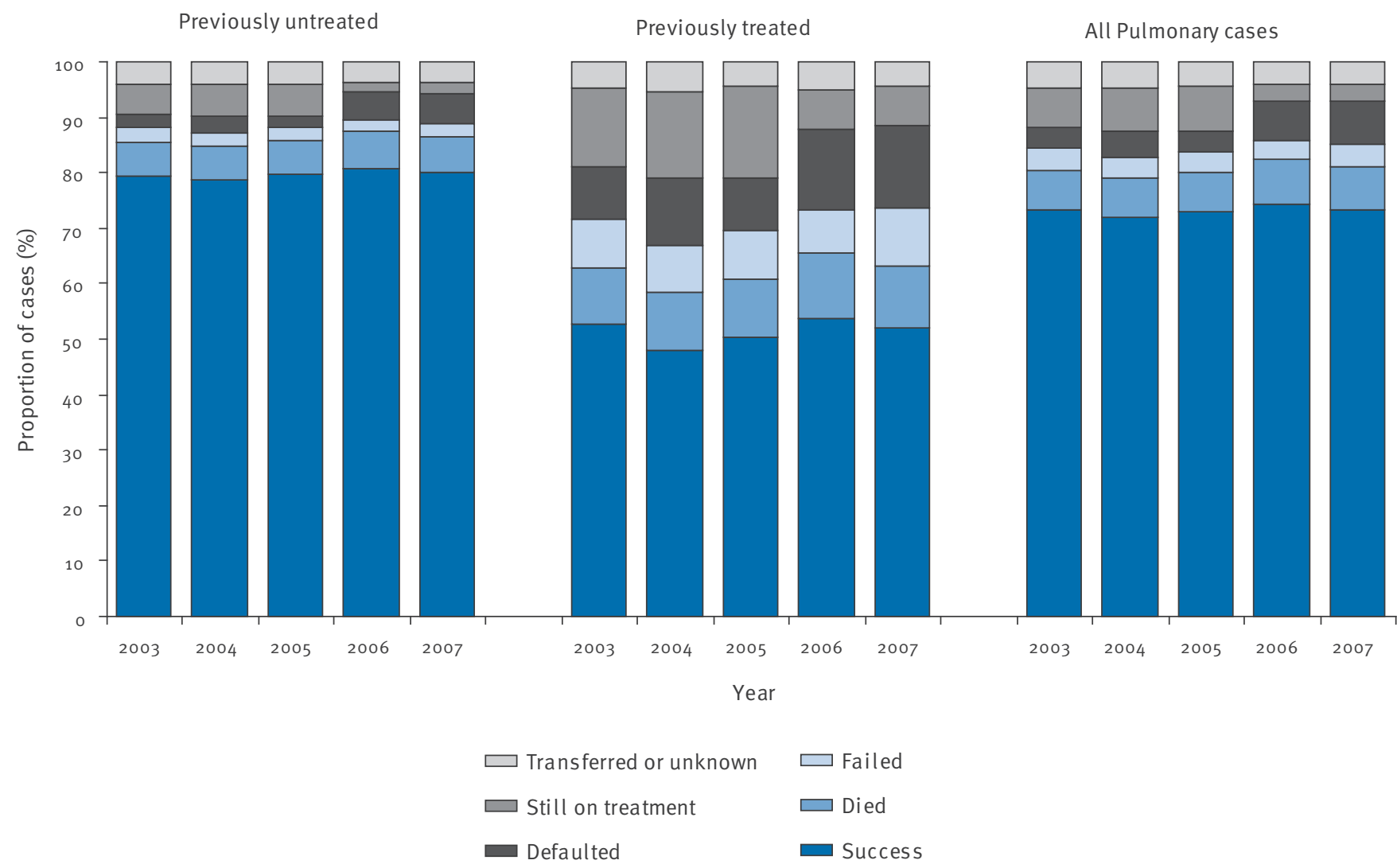

EEA: European Economic Area; EU: European Union.

Excluding countries that did not or not in all years report cases: Austria, Bulgaria, Finland, France, Greece, Liechtenstein, Luxembourg, and Spain. 
TABLE 1

Treatment outcome in new and retreatment culture-confirmed pulmonary tuberculosis cases, by country, EU/EEA countries, $2007(n=36,377)$

\begin{tabular}{|c|c|c|c|c|c|c|c|c|c|c|c|c|c|}
\hline \multirow[b]{2}{*}{ Country } & \multirow{2}{*}{$\begin{array}{c}\text { Cases notified } \\
\text { in } 2007 \\
\mathrm{~N} \\
\end{array}$} & \multicolumn{2}{|c|}{ Success } & \multicolumn{2}{|c|}{ Died } & \multicolumn{2}{|c|}{ Failed } & \multicolumn{2}{|c|}{ Defaulted } & \multicolumn{2}{|c|}{$\begin{array}{c}\text { Still on treat- } \\
\text { ment }\end{array}$} & \multicolumn{2}{|c|}{$\begin{array}{c}\text { Transferred or } \\
\text { unknown }\end{array}$} \\
\hline & & $\mathrm{N}$ & $(\%)$ & $\mathrm{N}$ & $(\%)$ & N & $(\%)$ & $\mathrm{N}$ & $(\%)$ & $\mathrm{N}$ & (\%) & $\mathrm{N}$ & $(\%)$ \\
\hline \multicolumn{14}{|l|}{ New cases } \\
\hline Austria & - & - & - & - & - & - & - & - & - & - & - & - & - \\
\hline Belgium $^{1}$ & 499 & 342 & $(68.5)$ & 42 & $(8.4)$ & 0 & $(0.0)$ & 44 & $(8.8)$ & 12 & $(2.4)$ & 59 & $(11.8)$ \\
\hline Bulgaria & 1,233 & 972 & $(78.8)$ & 85 & $(6.9)$ & 4 & $(0.3)$ & 96 & $(7.8)$ & 41 & $(3.3)$ & 35 & (2.8) \\
\hline Cyprus & - & - & - & - & - & - & - & - & - & - & - & - & - \\
\hline Czech Republic & 459 & 331 & $(72.1)$ & 86 & $(18.7)$ & 4 & $(0.9)$ & 32 & $(7.0)$ & 4 & $(0.9)$ & 2 & $(0.4)$ \\
\hline Denmark $^{1}$ & 213 & 169 & $(79.3)$ & 11 & $(5.2)$ & 2 & $(0.9)$ & 3 & $(1.4)$ & 11 & $(5.2)$ & 17 & $(8.0)$ \\
\hline Estonia & 302 & 185 & $(61.3)$ & 41 & $(13.6)$ & 2 & $(0.7)$ & 29 & $(9.6)$ & 45 & $(14.9)$ & 0 & $(0.0)$ \\
\hline Finland & 181 & 126 & $(69.6)$ & 35 & $(19.3)$ & 1 & $(0.6)$ & 2 & $(1.1)$ & 7 & $(3.9)$ & 10 & (5.5) \\
\hline France & - & - & - & - & - & - & - & - & - & - & - & - & - \\
\hline Germany & 2,421 & 1,863 & $(77.0)$ & 277 & $(11.4)$ & 3 & $(0.1)$ & 36 & $(1.5)$ & 69 & $(2.9)$ & 173 & (7.1) \\
\hline Greece & - & - & - & - & - & - & - & - & - & - & - & - & - \\
\hline Hungary & 612 & 311 & $(50.8)$ & 74 & $(12.1)$ & 86 & $(14.1)$ & 34 & $(5.6)$ & 84 & $(13.7)$ & 23 & (3.8) \\
\hline Iceland & 7 & 6 & $(85.7)$ & 0 & $(0.0)$ & 0 & $(0.0)$ & 0 & $(0.0)$ & 0 & $(0.0)$ & 1 & $(14.3)$ \\
\hline Ireland $^{1}$ & 181 & 127 & $(70.2)$ & 10 & $(5.5)$ & 0 & $(0.0)$ & 3 & $(1.7)$ & 8 & $(4.4)$ & 33 & $(18.2)$ \\
\hline Italy & - & - & - & - & - & - & - & - & - & - & - & - & - \\
\hline Latvia & 772 & 634 & $(82.1)$ & 54 & $(7.0)$ & 1 & $(0.1)$ & 32 & $(4.1)$ & 51 & $(6.6)$ & 0 & $(0.0)$ \\
\hline Liechtenstein & - & - & - & - & - & - & - & - & - & - & - & - & - \\
\hline Lithuania & 1,209 & 860 & $(71.1)$ & 144 & $(11.9)$ & 18 & (1.5) & 89 & $(7.4)$ & 94 & $(7.8)$ & 4 & $(0.3)$ \\
\hline Luxembourg & - & - & - & - & - & - & - & - & - & - & - & - & - \\
\hline Malta & 12 & 9 & $(75.0)$ & 0 & $(0.0)$ & 0 & $(0.0)$ & 1 & $(8.3)$ & 1 & $(8.3)$ & 1 & $(8.3)$ \\
\hline Netherlands ${ }^{1}$ & 397 & 314 & $(79.1)$ & 18 & $(4.5)$ & 0 & $(0.0)$ & 8 & $(2.0)$ & 0 & $(0.0)$ & 57 & $(14.4)$ \\
\hline Norway $^{1}$ & 114 & 89 & $(78.1)$ & 2 & $(1.8)$ & 0 & $(0.0)$ & 0 & $(0.0)$ & 4 & $(3.5)$ & 19 & $(16.7)$ \\
\hline Poland & 4,502 & 3,444 & $(76.5)$ & 269 & $(6.0)$ & 12 & $(0.3)$ & 448 & $(10.0)$ & 16 & $(0.4)$ & 313 & $(7.0)$ \\
\hline Portugal & 1,694 & 1,467 & $(86.6)$ & 90 & $(5.3)$ & 5 & $(0.3)$ & 52 & (3.1) & 56 & $(3.3)$ & 24 & $(1.4)$ \\
\hline Romania & 11,245 & 9,508 & $(84.6)$ & 453 & $(4.0)$ & 442 & (3.9) & 533 & $(4.7)$ & 95 & $(0.8)$ & 214 & (1.9) \\
\hline Slovakia & 304 & 260 & $(85.5)$ & 36 & $(11.8)$ & 1 & (0.3) & 5 & $(1.6)$ & 1 & $(0.3)$ & 1 & $(0.3)$ \\
\hline Slovenia & 150 & 123 & $(82.0)$ & 16 & $(10.7)$ & 0 & $(0.0)$ & 4 & $(2.7)$ & 0 & $(0.0)$ & 7 & $(4.7)$ \\
\hline Spain & - & - & - & - & - & - & - & - & - & - & - & - & - \\
\hline Sweden $^{1}$ & 237 & 157 & $(66.2)$ & 17 & $(7.2)$ & 0 & $(0.0)$ & 2 & $(0.8)$ & 8 & $(3.4)$ & 53 & $(22.4)$ \\
\hline United Kingdom ${ }^{1}$ & 2,241 & 1,733 & $(77.3)$ & 145 & $(6.5)$ & 0 & $(0.0)$ & 15 & $(0.7)$ & 128 & $(5.7)$ & 220 & (9.8) \\
\hline Total New cases & 28,985 & 23,030 & $(79.5)$ & 1,905 & $(6.6)$ & 581 & $(2.0)$ & 1,468 & $(5.1)$ & 735 & $(2.5)$ & 1,266 & $(4.4)$ \\
\hline \multicolumn{14}{|l|}{ Retreatment cases } \\
\hline Austria & - & - & - & - & - & - & - & - & - & - & - & - & - \\
\hline Belgium $^{2}$ & 49 & 27 & $(55.1)$ & 6 & $(12.2)$ & 0 & $(0.0)$ & 4 & $(8.2)$ & 8 & $(16.3)$ & 4 & $(8.2)$ \\
\hline Bulgaria & 146 & 52 & $(35.6)$ & 38 & $(26.0)$ & 2 & $(1.4)$ & 23 & (15.8) & 27 & $(18.5)$ & 4 & $(2.7)$ \\
\hline Cyprus & - & - & - & - & - & - & - & - & - & - & - & - & - \\
\hline Czech Republic & 44 & 30 & $(68.2)$ & 7 & $(15.9)$ & 0 & $(0.0)$ & 4 & $(9.1)$ & 2 & $(4.5)$ & 1 & $(2.3)$ \\
\hline Denmark $^{2}$ & 18 & 8 & $(44.4)$ & 3 & $(16.7)$ & 0 & $(0.0)$ & 1 & $(5.6)$ & 1 & $(5.6)$ & 5 & $(27.8)$ \\
\hline Estonia & 66 & 31 & $(47.0)$ & 5 & $(7.6)$ & 3 & (4.5) & 13 & (19.7) & 14 & $(21.2)$ & 0 & $(0.0)$ \\
\hline Finland & 7 & 7 & $(100.0)$ & 0 & $(0.0)$ & 0 & $(0.0)$ & 0 & $(0.0)$ & 0 & $(0.0)$ & 0 & $(0.0)$ \\
\hline France & - & - & - & - & - & - & - & - & - & - & - & - & - \\
\hline Germany & 178 & 114 & $(64.0)$ & 25 & $(14.0)$ & 3 & $(1.7)$ & 8 & $(4.5)$ & 13 & $(7.3)$ & 15 & $(8.4)$ \\
\hline Greece & - & - & - & - & - & - & - & - & - & - & - & - & - \\
\hline Hungary & 130 & 51 & $(39.2)$ & 26 & $(20.0)$ & 26 & $(20.0)$ & 12 & $(9.2)$ & 13 & $(10.0)$ & 2 & (1.5) \\
\hline Iceland & 1 & 0 & $(0.0)$ & 0 & $(0.0)$ & 0 & $(0.0)$ & 0 & $(0.0)$ & 0 & $(0.0)$ & 1 & $(100.0)$ \\
\hline$\left.\right|_{\text {reland }} ^{2}$ & 28 & 16 & $(57.1)$ & 4 & $(14.3)$ & 0 & $(0.0)$ & 0 & $(0.0)$ & 3 & $(10.7)$ & 5 & (17.9) \\
\hline Italy & - & - & - & - & - & - & - & - & - & - & - & - & - \\
\hline Latvia & 167 & 96 & $(57.5)$ & 14 & $(8.4)$ & 2 & $(1.2)$ & 17 & $(10.2)$ & 36 & $(21.6)$ & 2 & $(1.2)$ \\
\hline Liechtenstein & - & - & - & - & - & - & - & - & - & - & - & - & - \\
\hline Lithuania & 423 & 130 & $(30.7)$ & 119 & $(28.1)$ & 21 & $(5.0)$ & 89 & $(21.0)$ & 63 & $(14.9)$ & 1 & $(0.2)$ \\
\hline
\end{tabular}




\begin{tabular}{|c|c|c|c|c|c|c|c|c|c|c|c|c|c|}
\hline Luxembourg & - & - & - & - & - & - & - & - & - & - & - & - & - \\
\hline Malta & 1 & 0 & $(0.0)$ & 0 & $(0.0)$ & 0 & $(0.0)$ & 0 & $(0.0)$ & 0 & $(0.0)$ & 1 & $(100.0)$ \\
\hline Netherlands ${ }^{2}$ & 40 & 27 & $(67.5)$ & 3 & $(7.5)$ & 0 & $(0.0)$ & 1 & $(2.5)$ & 0 & $(0.0)$ & 9 & (22.5) \\
\hline Norway $^{2}$ & 17 & 13 & $(76.5)$ & 1 & $(5.9)$ & 0 & $(0.0)$ & 0 & $(0.0)$ & 1 & $(5.9)$ & 2 & $(11.8)$ \\
\hline Poland & 698 & 429 & $(61.5)$ & 69 & (9.9) & 4 & $(0.6)$ & 141 & $(20.2)$ & 8 & $(1.1)$ & 47 & $(6.7)$ \\
\hline Portugal & 182 & 140 & (76.9) & 13 & $(7.1)$ & 0 & $(0.0)$ & 11 & $(6.0)$ & 12 & (6.6) & 6 & (3.3) \\
\hline Romania & 4,933 & 2,462 & (49.9) & 479 & $(9.7)$ & 683 & (13.8) & 767 & $(15.5)$ & 325 & (6.6) & 217 & (4.4) \\
\hline Slovakia & 42 & 35 & $(83.3)$ & 1 & $(2.4)$ & 1 & $(2.4)$ & 1 & $(2.4)$ & 4 & $(9.5)$ & 0 & $(0.0)$ \\
\hline Slovenia & 13 & 10 & $(76.9)$ & 3 & $(23.1)$ & 0 & $(0.0)$ & 0 & $(0.0)$ & 0 & $(0.0)$ & 0 & $(0.0)$ \\
\hline Spain & - & - & - & - & - & - & - & - & - & - & - & - & - \\
\hline Sweden $^{2}$ & 13 & 7 & $(53.8)$ & 2 & $(15.4)$ & 0 & $(0.0)$ & 1 & $(7.7)$ & 1 & $(7.7)$ & 2 & $(15.4)$ \\
\hline United Kingdom² & 196 & 141 & $(71.9)$ & 22 & $(11.2)$ & 0 & $(0.0)$ & 0 & $(0.0)$ & 14 & $(7.1)$ & 19 & $(9.7)$ \\
\hline Total retreatment & 7,392 & 3,826 & $(51.8)$ & 840 & $(11.4)$ & 745 & $(10.1)$ & 1,093 & $(14.8)$ & 545 & $(7.4)$ & 343 & $(4.6)$ \\
\hline Total for all & 36,377 & 26,856 & (73.8) & 2,745 & (7.5) & 1,326 & (3.6) & 2,561 & $(7.0)$ & 1,280 & (3.5) & 1,609 & (4.4) \\
\hline
\end{tabular}

EEA: European Economic Area; EU: European Union.

${ }^{1}$ Not previously diagnosed cases.

${ }^{2}$ Previously diagnosed cases.

\section{TABLE 2}

Treatment outcome in culture-confirmed pulmonary TB cases by geographic origin and by country, EU/EEA countries, $2007(n=37,160)$

\begin{tabular}{|c|c|c|c|c|c|c|c|c|c|c|c|c|c|}
\hline \multirow[b]{2}{*}{ Country } & \multirow{2}{*}{$\begin{array}{c}\text { Cases } \\
\text { N }\end{array}$} & \multicolumn{2}{|c|}{ Success } & \multicolumn{2}{|c|}{ Died } & \multicolumn{2}{|c|}{ Failed } & \multicolumn{2}{|c|}{ Defaulted } & \multicolumn{2}{|c|}{ Still on treatment } & \multicolumn{2}{|c|}{$\begin{array}{c}\text { Transferred or } \\
\text { unknown }\end{array}$} \\
\hline & & N & (\%) & N & (\%) & N & (\%) & N & (\%) & N & (\%) & $\mathbf{N}$ & (\%) \\
\hline \multicolumn{14}{|l|}{ National origin } \\
\hline Austria & - & - & - & - & - & - & - & - & - & - & - & - & - \\
\hline Belgium & 327 & 224 & $(68.5)$ & 42 & $(12.8)$ & 0 & $(0.0)$ & 14 & $(4.3)$ & 8 & $(2.4)$ & 39 & $(11.9)$ \\
\hline Bulgaria & 1,379 & 1,024 & $(74.2)$ & 123 & $(8.9)$ & 6 & $(0.4)$ & 119 & $(8.6)$ & 68 & $(4.9)$ & 39 & $(2.8)$ \\
\hline Cyprus & - & - & - & - & - & - & - & - & - & - & - & - & - \\
\hline Czech Republic & 407 & 306 & $(75.2)$ & 84 & $(20.6)$ & 3 & $(0.7)$ & 9 & $(2.2)$ & 5 & (1.2) & 0 & $(0.0)$ \\
\hline Denmark $^{1}$ & 113 & 89 & $(78.8)$ & 10 & $(8.8)$ & 1 & $(0.9)$ & 1 & $(0.9)$ & 4 & (3.5) & 8 & (7.1) \\
\hline Estonia & 312 & 184 & $(59.0)$ & 38 & $(12.2)$ & 3 & $(1.0)$ & 36 & $(11.5)$ & 51 & (16.3) & 0 & $(0.0)$ \\
\hline Finland & 146 & 99 & $(67.8)$ & 35 & $(24.0)$ & 1 & $(0.7)$ & 1 & $(0.7)$ & 5 & (3.4) & 5 & (3.4) \\
\hline France & - & - & - & - & - & - & - & - & - & - & - & - & - \\
\hline Germany & 1,680 & 1,214 & $(72.3)$ & 292 & $(17.4)$ & 6 & $(0.4)$ & 28 & $(1.7)$ & 47 & $(2.8)$ & 93 & (5.5) \\
\hline Greece & - & - & - & - & - & - & - & - & - & - & - & - & - \\
\hline Hungary & 719 & 345 & $(48.0)$ & 100 & (13.9) & 113 & $(15.7)$ & 43 & $(6.0)$ & 94 & $(13.1)$ & 24 & (3.3) \\
\hline Iceland & 1 & 1 & $(100.0)$ & 0 & $(0.0)$ & 0 & $(0.0)$ & 0 & $(0.0)$ & 0 & $(0.0)$ & 0 & $(0.0)$ \\
\hline Ireland & 149 & 103 & $(69.1)$ & 14 & $(9.4)$ & 0 & $(0.0)$ & 3 & $(2.0)$ & 2 & (1.3) & 27 & (18.1) \\
\hline Italy & - & - & - & - & - & - & - & - & - & - & - & - & - \\
\hline Latvia & 887 & 691 & $(77.9)$ & 66 & $(7.4)$ & 3 & $(0.3)$ & 44 & $(5.0)$ & 82 & $(9.2)$ & 1 & $(0.1)$ \\
\hline Liechtenstein & - & - & - & - & - & - & - & - & - & - & - & - & - \\
\hline Lithuania & 1,593 & 971 & $(61.0)$ & 258 & $(16.2)$ & 36 & (2.3) & 172 & (10.8) & 151 & $(9.5)$ & 5 & $(0.3)$ \\
\hline Luxembourg & - & - & - & - & - & - & - & - & - & - & - & - & - \\
\hline Malta & 5 & 4 & $(80.0)$ & 0 & $(0.0)$ & 0 & $(0.0)$ & 0 & $(0.0)$ & 0 & $(0.0)$ & 1 & $(20.0)$ \\
\hline Netherlands & 198 & 148 & $(74.7)$ & 19 & $(9.6)$ & 0 & $(0.0)$ & 6 & (3.0) & 0 & $(0.0)$ & 25 & $(12.6)$ \\
\hline Norway & 26 & 21 & $(80.8)$ & 3 & $(11.5)$ & 0 & $(0.0)$ & 0 & $(0.0)$ & 0 & $(0.0)$ & 2 & $(7.7)$ \\
\hline Poland & 5,178 & 3,863 & $(74.6)$ & 338 & $(6.5)$ & 16 & $(0.3)$ & 586 & (11.3) & 24 & $(0.5)$ & 351 & $(6.8)$ \\
\hline Portugal & 1,622 & 1,397 & $(86.1)$ & 93 & $(5.7)$ & 5 & $(0.3)$ & 48 & $(3.0)$ & 56 & $(3.5)$ & 23 & (1.4) \\
\hline Romania & 16,178 & 11,970 & $(74.0)$ & 932 & $(5.8)$ & 1,125 & $(7.0)$ & 1,300 & $(8.0)$ & 420 & $(2.6)$ & 431 & $(2.7)$ \\
\hline Slovakia & 346 & 296 & $(85.5)$ & 38 & $(11.0)$ & 2 & $(0.6)$ & 6 & $(1.7)$ & 4 & $(1.2)$ & 0 & $(0.0)$ \\
\hline Slovenia & 128 & 106 & $(82.8)$ & 17 & $(13.3)$ & 0 & $(0.0)$ & 4 & (3.1) & 0 & $(0.0)$ & 1 & $(0.8)$ \\
\hline Spain & - & - & - & - & - & - & - & - & - & - & - & - & - \\
\hline Sweden & 66 & 37 & $(56.1)$ & 12 & $(18.2)$ & 0 & $(0.0)$ & 1 & $(1.5)$ & 1 & $(1.5)$ & 15 & $(22.7)$ \\
\hline United Kingdom & 915 & 673 & $(73.6)$ & 113 & $(12.3)$ & 0 & $(0.0)$ & 7 & $(0.8)$ & 44 & $(4.8)$ & 78 & $(8.5)$ \\
\hline
\end{tabular}




\begin{tabular}{|c|c|c|c|c|c|c|c|c|c|c|c|c|c|}
\hline Total Nationals & 32,380 & 23,765 & $(73.4)$ & 2,628 & $(8.1)$ & 1,320 & $(4.1)$ & 2,428 & $(7.5)$ & 1,066 & (3.3) & 1,173 & (3.6) \\
\hline \multicolumn{14}{|l|}{ Foreign origin } \\
\hline Austria & - & - & - & - & - & - & - & - & - & - & - & - & \\
\hline Belgium & 288 & 190 & $(66.0)$ & 17 & (5.9) & 0 & $(0.0)$ & 39 & $(13.5)$ & 13 & $(4.5)$ & 29 & (10.1) \\
\hline Bulgaria & 1 & 1 & $(100.0)$ & 0 & $(0.0)$ & 0 & $(0.0)$ & 0 & $(0.0)$ & 0 & $(0.0)$ & 0 & $(0.0)$ \\
\hline Cyprus & - & - & - & - & - & - & - & - & - & - & - & - & - \\
\hline Czech Republic & 96 & 55 & $(57.3)$ & 9 & $(9.4)$ & 1 & $(1.0)$ & 27 & $(28.1)$ & 1 & $(1.0)$ & 3 & (3.1) \\
\hline Denmark $^{2}$ & 118 & 88 & $(74.6)$ & 4 & $(3.4)$ & 1 & $(0.8)$ & 3 & $(2.5)$ & 8 & $(6.8)$ & 14 & $(11.9)$ \\
\hline Estonia & 56 & 32 & $(57.1)$ & 8 & $(14.3)$ & 2 & (3.6) & 6 & $(10.7)$ & 8 & $(14.3)$ & 0 & $(0.0)$ \\
\hline Finland & 42 & 34 & $(81.0)$ & 0 & $(0.0)$ & 0 & $(0.0)$ & 1 & $(2.4)$ & 2 & $(4.8)$ & 5 & $(11.9)$ \\
\hline France & - & - & - & - & - & - & - & - & - & - & - & - & - \\
\hline Germany & 1,157 & 914 & $(79.0)$ & 66 & $(5.7)$ & 1 & $(0.1)$ & 24 & $(2.1)$ & 37 & $(3.2)$ & 115 & (9.9) \\
\hline Greece & - & - & - & - & - & - & - & - & - & - & - & - & - \\
\hline Hungary & 24 & 14 & $(58.3)$ & 0 & $(0.0)$ & 3 & $(12.5)$ & 4 & $(16.7)$ & 3 & $(12.5)$ & 0 & $(0.0)$ \\
\hline Iceland & 7 & 5 & $(71.4)$ & 0 & $(0.0)$ & 0 & $(0.0)$ & 0 & $(0.0)$ & 0 & $(0.0)$ & 2 & $(28.6)$ \\
\hline Ireland & 95 & 62 & $(65.3)$ & 3 & $(3.2)$ & 0 & $(0.0)$ & 0 & $(0.0)$ & 9 & $(9.5)$ & 21 & $(22.1)$ \\
\hline Italy & - & - & - & - & - & - & - & - & - & - & - & - & - \\
\hline Latvia & 52 & 39 & $(75.0)$ & 2 & (3.8) & 0 & $(0.0)$ & 5 & $(9.6)$ & 5 & $(9.6)$ & 1 & $(1.9)$ \\
\hline Liechtenstein & - & - & - & - & - & - & - & - & - & - & - & - & - \\
\hline Lithuania & 43 & 21 & $(48.8)$ & 7 & $(16.3)$ & 3 & $(7.0)$ & 6 & $(14.0)$ & 6 & $(14.0)$ & 0 & $(0.0)$ \\
\hline Luxembourg & 18 & 0 & $(0.0)$ & 0 & $(0.0)$ & 0 & $(0.0)$ & 0 & $(0.0)$ & 0 & $(0.0)$ & 18 & $(100.0)$ \\
\hline Malta & 9 & 5 & $(55.6)$ & 0 & $(0.0)$ & 0 & $(0.0)$ & 1 & $(11.1)$ & 1 & $(11.1)$ & 2 & $(22.2)$ \\
\hline Netherlands & 285 & 216 & $(75.8)$ & 10 & $(3.5)$ & 0 & $(0.0)$ & 4 & $(1.4)$ & 0 & $(0.0)$ & 55 & (19.3) \\
\hline Norway & 121 & 90 & $(74.4)$ & 2 & $(1.7)$ & 0 & $(0.0)$ & 0 & $(0.0)$ & 5 & $(4.1)$ & 24 & $(19.8)$ \\
\hline Poland & 22 & 10 & $(45.5)$ & 0 & $(0.0)$ & 0 & $(0.0)$ & 3 & (13.6) & 0 & $(0.0)$ & 9 & $(40.9)$ \\
\hline Portugal & 249 & 208 & $(83.5)$ & 8 & $(3.2)$ & 0 & $(0.0)$ & 15 & $(6.0)$ & 12 & $(4.8)$ & 6 & $(2.4)$ \\
\hline Romania & 0 & 0 & - & 0 & - & 0 & - & 0 & - & 0 & - & 0 & - \\
\hline Slovakia & 4 & 2 & $(50.0)$ & 0 & $(0.0)$ & 0 & $(0.0)$ & 0 & $(0.0)$ & 1 & $(25.0)$ & 1 & $(25.0)$ \\
\hline Slovenia & 35 & 27 & $(77.1)$ & 2 & $(5.7)$ & 0 & $(0.0)$ & 0 & $(0.0)$ & 0 & $(0.0)$ & 6 & $(17.1)$ \\
\hline Spain & - & - & - & - & - & - & - & - & - & - & - & - & - \\
\hline Sweden & 184 & 127 & $(69.0)$ & 7 & (3.8) & 0 & $(0.0)$ & 2 & $(1.1)$ & 8 & $(4.3)$ & 40 & $(21.7)$ \\
\hline United Kingdom & 1,874 & 1,467 & $(78.3)$ & 82 & $(4.4)$ & 0 & $(0.0)$ & 11 & $(0.6)$ & 106 & $(5.7)$ & 208 & $(11.1)$ \\
\hline Total Foreigners & 4,780 & 3,607 & $(75.5)$ & 227 & $(4.7)$ & 11 & $(0.2)$ & 151 & (3.2) & 225 & $(4.7)$ & 559 & $(11.7)$ \\
\hline
\end{tabular}

EEA: European Economic Area; EU: European Union.

${ }^{1}$ Excluding native cases 26 years old whose parents were born outside Denmark

${ }^{2}$ Including native cases < 26 years old whose parents were born outside Denmark

\section{FIGURE 2}

Proportion of tuberculosis deaths by geographic origin, EU/EEA countries ${ }^{1}, 2007$ (of n=37,160 cases)

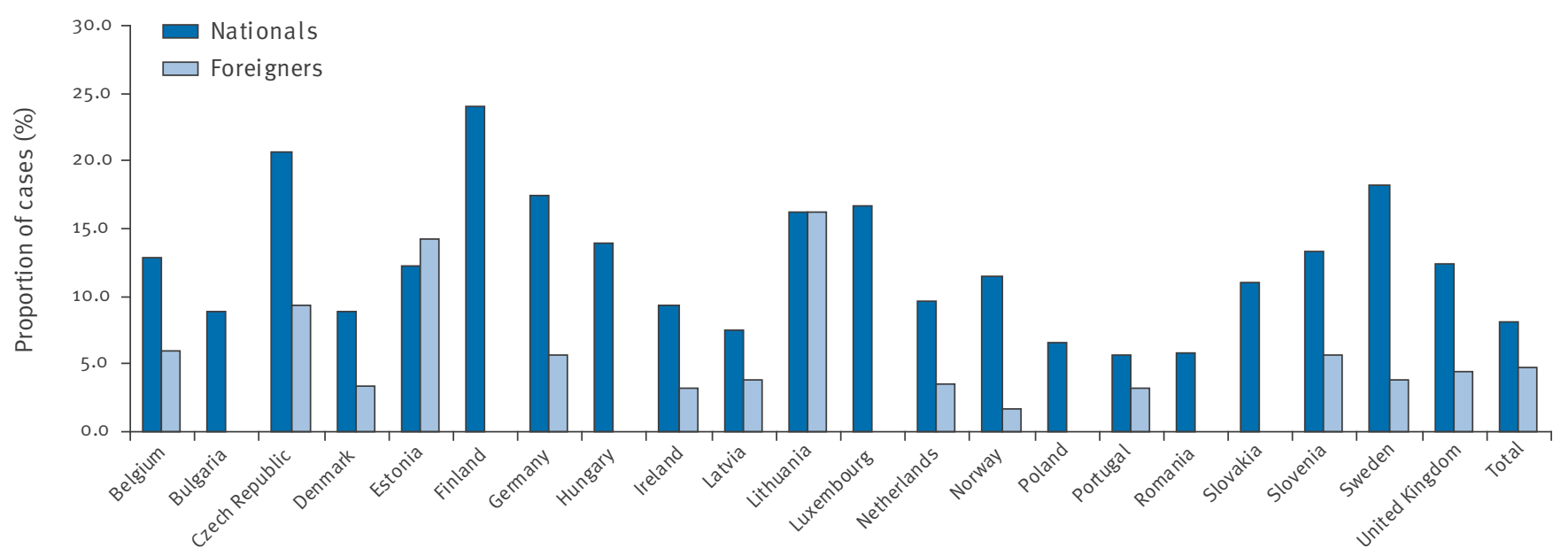

EEA: European Economic Area; EU: European Union.

${ }^{1}$ Excluding countries that did not or not in all years report cases. 
TB cases. The following case classification was used for the purpose of the analysis:

- A laboratory-confirmed TB case was a patient with culture-confirmed disease due to Mycobacterium tuberculosis complex.

- A new case was any case who had not received drug treatment for active TB in the past, or who received anti-TB drugs for less than one month.

- A retreatment case was a case diagnosed with TB in the past and who received treatment with antiTB drugs (excluding preventive therapy) for at least one month.

- A pulmonary case was any case with TB affecting the lung parenchyma, the tracheo-bronchial tree or the larynx.

- Multi-drug resistance was defined as resistance to at least isoniazid and rifampicin.

- Foreign/national origin for comparison of treatment outcome by geographical origin of TB cases was classified according to place of birth: born in the country (national origin) or born outside the country (foreign origin). For countries reporting citizenship rather than place of birth, the former was used as a proxy of national/foreign origin. In Denmark, the place of birth of parents was also used to classify geographical origin.

For the purpose of this analysis, internationally recommended outcome categories where used with two additional categories [9]: 'still on treatment' after 12 months of treatment, and 'unknown'. Adopted definitions in our study were:

- Cured: The treatment has been completed and culture has become negative on samples taken at the end of treatment and on at least one previous occasion.

- Completed: The treatment has been completed but the case does not meet the criteria for cure or treatment failure.

- Failed: Culture or sputum smear remain positive or become positive again five months or later into the course of treatment.

- Died: Death, irrespective of cause, occurred before the patient was cured or treatment was completed.

- Defaulted: The treatment was interrupted for two months or more, not resulting from a decision of the care provider; or the patient was lost to followup for two months or more before the end of treatment, except if transferred.

- Transferred: The patient was referred to another clinical unit for treatment, and information on outcome is not available.

- Still on treatment: The patient is still on treatment at 12 (24 when applicable) months after the start of treatment and did not meet any other outcome during treatment. This category includes patients whose initial treatment was changed due to polyresistance (i.e. resistance to at least two first-line drugs) of the isolate taken at the start of treatment, whose treatment was prolonged because of side effects/complications, whose initial regimen had been planned for more than 12 months, or patients for whom information on the reasons for being still on treatment was not available.

- Unknown: Information on outcome is not available, for cases not known to have been transferred.

- Success: This refers to the combined number of patients belonging to the treatment categories 'cured' and 'completed'. The success rate target (established by the WHA as $85 \%$ of new smear-positive cases) has been adapted to the EU/EEA setting where bacteriological confirmation of cases is done by culture. Thus for the purposes of this study, a success rate target of $85 \%$ applies to new laboratory-confirmed cases.

- Cohort: This includes all cases eligible for outcome analysis (cohorts); i.e. all the culture-confirmed pulmonary TB cases notified in the calendar year of interest, after exclusion of cases with final diagnosis other than TB.

For the purpose of calculating the outcome variables, culture-confirmed pulmonary TB cases notified in the calendar year of interest were used as denominators. Data for one country were considered to be complete if the cohorts used as denominators included all culture-confirmed pulmonary TB cases notified in the year selected for analysis and if the combined total of 'defaulted, transferred and unknown' cases did not exceed $35 \%$ of cases notified in that year.

Proportions of deaths by geographic origin were stratified by age to allow comparability.

Adjustments to account for how countries with high numbers of cases influence the EU/EEA average were not performed as the study aimed at presenting overall figures for EU/EEA patients.

\section{FIGURE 3}

Age-stratified case fatality by geographic origin, EU/EEA countries, 2007 (of $n=25,391$ cases)

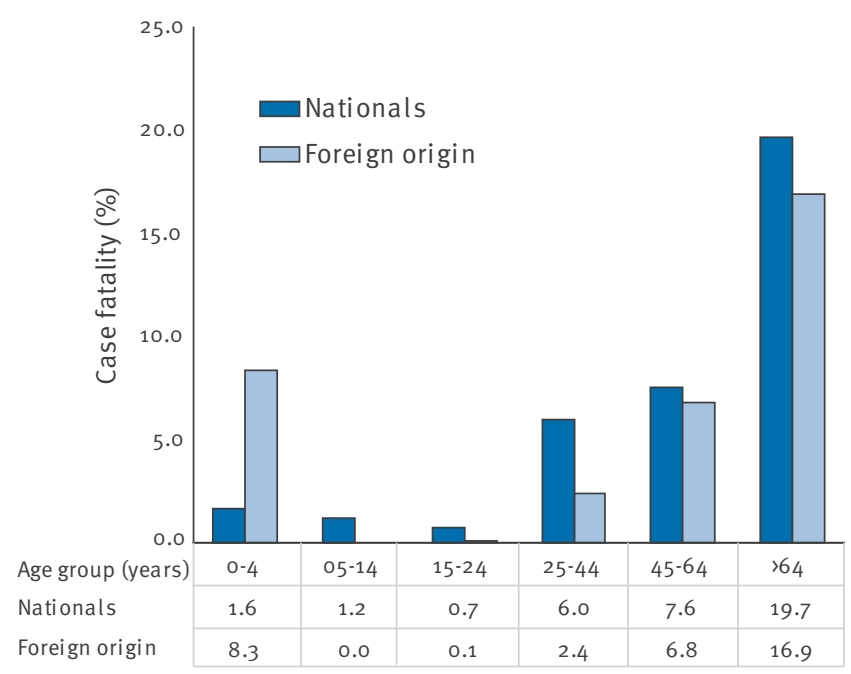

EEA: European Economic Area; EU: European Union. 


\section{Results}

Twenty-two countries reported TOM data at 12 months for culture-confirmed pulmonary TB cases reported in 2007. Data were considered to be complete as per study definition in all reporting countries. The overall treatment success rate for all laboratory-confirmed pulmonary cases was $73.8 \%$. Of these patients, $7.5 \%$ died while being treated for TB, 3.6\% failed treatment, $7.0 \%$ defaulted, $3.5 \%$ were still on treatment at the end of the 12 -month observation period and 4,4\% had an outcome recorded as unknown or transferred (Figure 1, Table 1).

Among new laboratory-confirmed pulmonary cases, $79.5 \%$ had a successful outcome, $6.6 \%$ died, $2 \%$ failed, $2.5 \%$ were still on treatment, and $4.4 \%$ were transferred or had an unknown outcome (Table 1). Among countries with more than 20 new culture-confirmed pulmonary cases, success rates varied widely from $50.8 \%$ in Hungary to $86.6 \%$ and $85.5 \%$ in Portugal and Slovakia respectively. Three countries achieved treatment success in $85 \%$ or more of this category of cases: Iceland, $85.7 \%$, Portugal, $86.6 \%$ and Slovakia, $85.5 \%$. The percentage of cases that died while undergoing TB treatment ranged from $1.8 \%$ in Norway to $18.7 \%$ in the Czech Republic. Overall treatment success rates below $75 \%$ were associated with a high loss to follow-up (defaulted and transferred or unknown) ranging from $6.6 \%$ to $25.7 \%$.

Treatment outcomes for retreatment culture-confirmed pulmonary TB cases were reported from 22 EU/EEA Member States (Table 1). For seven countries, information about previous treatment was not distinguished and reported as previously diagnosed cases (Belgium, Denmark, Ireland, the Netherlands, Norway, Sweden and United Kingdom). Among these retreatment cases the overall success rate was lower (51.8\%; range: 0\%-100\%) than among new cases. Death (11.4\%), treatment failure (10.1\%), default (14.8\%) and still on treatment $(7.4 \%)$ were more frequently reported in this group than among new cases. Only six countries achieved a treatment success of at least $70 \%$ among retreatment cases (Table 1 ).

Analysis of data by geographic origin revealed similar proportions of successfully treated cases of national origin $(73.4 \%)$ and those of foreign origin (75.5\%). However, marked differences were observed in the proportion of deaths, with higher percentages among cases of national origin (8.1\%) compared with those of foreign origin ( $4.7 \%)$. Similarly, differences were found in the percentages of failed cases $(4.1 \%$ in nationals versus $0.2 \%$ in cases of foreign origin) and transferred/ unknown $(3.6 \%$ in nationals versus $11.7 \%$ in cases of foreign origin) (Table 2, Figure 2).

With regards to the differences in proportion of deaths between foreign origin and national cases, the stratification of case fatality by age group (Figure 3) reveals that age acts as an effect modifier, where the proportion of deaths increased with increasing age. The highest case fatality was in the age group of over 64 -year-olds, regardless of geographical origin. The high case fatality in 0-4-year-old children in the group of foreign origin is a doubtful interpretation as there was only one death in this group.

Fifteen countries (12 of which provided complete data as per study definition) reported the treatment outcome at 24 months for culture-confirmed MDR TB cases (new and retreatment). The overall treatment success in the 15 countries ranged from $19.8 \%$ to $100 \%$. Of the entire cohort, $16.6 \%$ died while on treatment, $17.0 \%$ failed treatment and $13.2 \%$ defaulted. $17.0 \%$ of registered cases were still on treatment at the end of the 24 months observation period and $5.3 \%$ had been transferred or had an unknown outcome (Table 3).

Analysis of trends for the cohorts 2003 to 2007 did not reveal any significant difference in the proportions of cases belonging to any of the treatment outcome categories. Treatment success remained in the range of $78 \%$ to $80 \%$ in the new laboratory-confirmed pulmonary cases. Minimal improvement from $48 \%$ to $52.2 \%$ was recorded between the 2006 and 2007 cohorts of retreatment culture-confirmed pulmonary cases (Figure 1).

\section{Discussion and conclusions}

This analysis of treatment outcome monitoring within the EU and EEA Member States revealed significant findings concerning TB control in the region. Firstly, it is a matter of concern that there has been only a marginal improvement in the number of countries reporting treatment outcomes to the EU-wide database, which increased by only one Member State compared with the 2006 cohort reporting (22 versus 21 countries). Similarly, the number of cases with an unknown treatment outcome because of transfer or 'outcome unknown', remained high with an average of $4.4 \%$ of all pulmonary culture-confirmed cases belonging to this category and with six of 22 countries reporting more than $10 \%$ of unknown outcomes. This represents a programmatic weakness in one of the pillars of TB control and highlights the importance of the monitoring and evaluation process $[2,3,10]$.

More disturbing is the fact that there has been no significant improvement in the percentage of cases successfully treated over the past five years, with $79.5 \%$ of new laboratory-confirmed pulmonary cases successfully treated and $51.8 \%$ in retreatment cases. This is reflected at the level of the individual Member States: only three countries achieved the target of $85 \%$ success rate in 2007 compared with seven countries for the 2006 cohort.

The authors would have wished to extend the analysis of completeness of treatment to all notified cases to gain further insight in the distribution and quality of outcomes; however data proved insufficient to pro- 
ceed with this approach since only few countries report treatment completion for all cases.

Achieving high success rates becomes particularly important in a setting like the EU and EEA where the decline in incidence that was typical of the past few decades is becoming slower in most countries [2]. This trend is certainly influenced by many factors including importation of cases from high-burden countries, outbreaks among vulnerable populations, persisting MDR $T B$, and in some cases a lack of adequate TB control measures. In this setting it is essential to achieve optimal treatment success in all TB patients.

The need for reaching the success rate target is justified by its potential epidemiological impact. Several epidemiological models have shown [11-14] that achieving the $85 \%$ success target coupled with a case detection of at least $70 \%$ would cause a decline in the annual TB incidence rate of $5-10 \%$ in the absence of co-infection with human immunodeficiency virus (HIV). These theoretical assumptions are further corroborated by empirical findings, particularly in the European context. In fact, the TB incidence has been declining rapidly all over Europe over the past century, but the decline has more than doubled following the introduction of effective treatment.

The analysis of the data by geographical origin (national versus foreign) revealed a similarity in the two groups in terms of overall success rate. Differences exist in the distribution of negative outcomes with regard to geographic origin. However, stratifying case fatality by age showed that the excess proportion of deaths

\section{TABLE 3}

Treatment outcome of multidrug-resistant tuberculosis cases after 24 months of treatment, EU/EEA countries, 2006 cohort $(\mathrm{n}=1,190)$

\begin{tabular}{|c|c|c|c|c|c|c|c|c|c|c|c|c|c|}
\hline \multirow{3}{*}{ Country } & \multirow{3}{*}{$\begin{array}{l}\text { Total number of } \\
\text { MDR cases }\end{array}$} & \multicolumn{12}{|c|}{ TOM after 24 months } \\
\hline & & \multicolumn{2}{|c|}{ Success } & \multicolumn{2}{|c|}{ Died } & \multicolumn{2}{|c|}{ Failed } & \multicolumn{2}{|c|}{ Defaulted } & \multicolumn{2}{|c|}{$\begin{array}{c}\text { Still on treat- } \\
\text { ment }\end{array}$} & \multicolumn{2}{|c|}{$\begin{array}{c}\text { Transferred or } \\
\text { unknown }\end{array}$} \\
\hline & & N & $\%$ & $\mathbf{N}$ & $\%$ & N & $\%$ & $\mathbf{N}$ & $\%$ & N & $\%$ & $\mathbf{N}$ & $\%$ \\
\hline Austria & - & - & - & - & - & - & - & - & - & - & - & - & - \\
\hline Belgium & 18 & 10 & $(55.6)$ & 1 & (5.6) & 0 & $(0.0)$ & 0 & $(0.0)$ & 3 & $(16.7)$ & 4 & $(22.2)$ \\
\hline Bulgaria & - & - & - & - & - & - & - & - & - & - & - & - & - \\
\hline Cyprus & 0 & - & - & - & - & - & - & - & - & - & - & - & - \\
\hline Czech Republic & 12 & 3 & $(25.0)$ & 4 & $(33.3)$ & 0 & $(0.0)$ & 3 & $(25.0)$ & 2 & $(16.7)$ & 0 & $(0.0)$ \\
\hline Denmark & 3 & 2 & $(66.7)$ & 0 & $(0.0)$ & 0 & $(0.0)$ & 0 & $(0.0)$ & 1 & $(33.3)$ & 0 & $(0.0)$ \\
\hline Estonia & 53 & 24 & $(45.3)$ & 12 & $(22.6)$ & 2 & (3.8) & 14 & $(26.4)$ & 1 & $(1.9)$ & 0 & $(0.0)$ \\
\hline Finland & - & - & - & - & - & - & - & - & - & - & - & - & - \\
\hline France & - & - & - & - & - & - & - & - & - & - & - & - & - \\
\hline Germany & 83 & 42 & $(50.6)$ & 4 & $(4.8)$ & 1 & $(1.2)$ & 10 & $(12.0)$ & 14 & $(16.9)$ & 12 & $(14.5)$ \\
\hline Greece & - & - & - & - & - & - & - & - & - & - & - & - & - \\
\hline Hungary & 17 & 9 & $(52.9)$ & 1 & (5.9) & 5 & $(29.4)$ & 1 & (5.9) & 1 & (5.9) & 0 & $(0.0)$ \\
\hline Iceland & 0 & - & - & - & - & - & - & - & - & - & - & - & - \\
\hline Ireland & 4 & 1 & $(25.0)$ & 0 & $(0.0)$ & 0 & $(0.0)$ & 1 & $(25.0)$ & 0 & $(0.0)$ & 2 & $(50.0)$ \\
\hline Italy & - & - & - & - & - & - & - & - & - & - & - & - & - \\
\hline Latvia & 142 & 87 & $(61.3)$ & 34 & (23.9) & 6 & $(4.2)$ & 15 & $(10.6)$ & 0 & $(0.0)$ & 0 & $(0.0)$ \\
\hline Liechtenstein & - & - & - & - & - & - & - & - & - & - & - & - & - \\
\hline Lithuania & - & - & - & - & - & - & - & - & - & - & - & - & - \\
\hline Luxembourg & 0 & - & - & - & - & - & - & - & - & - & - & - & - \\
\hline Malta & 2 & 2 & $(100.0)$ & 0 & $(0.0)$ & 0 & $(0.0)$ & 0 & $(0.0)$ & 0 & $(0.0)$ & 0 & $(0.0)$ \\
\hline Netherlands & - & - & - & - & - & - & - & - & - & - & - & - & - \\
\hline Norway & 3 & 1 & $(33.3)$ & 0 & $(0.0)$ & 0 & $(0.0)$ & 0 & $(0.0)$ & 0 & $(0.0)$ & 2 & $(66.7)$ \\
\hline Poland & 32 & 11 & $(34.4)$ & 4 & $(12.5)$ & 3 & $(9.4)$ & 4 & (12.5) & 0 & $(0.0)$ & 10 & $(31.3)$ \\
\hline Portugal & 25 & 16 & $(64.0)$ & 6 & $(24.0)$ & 1 & $(4.0)$ & 2 & $(8.0)$ & 0 & $(0.0)$ & 0 & $(0.0)$ \\
\hline Romania & 788 & 156 & $(19.8)$ & 130 & $(16.5)$ & 184 & $(23.4)$ & 107 & (13.6) & 178 & $(22.6)$ & 33 & $(4.2)$ \\
\hline Slovakia & 7 & 3 & $(42.9)$ & 2 & $(28.6)$ & 0 & $(0.0)$ & 0 & $(0.0)$ & 2 & $(28.6)$ & 0 & $(0.0)$ \\
\hline Slovenia & 1 & 1 & $(100.0)$ & 0 & $(0.0)$ & 0 & $(0.0)$ & 0 & $(0.0)$ & 0 & $(0.0)$ & 0 & $(0.0)$ \\
\hline Spain & - & - & - & - & - & - & - & - & - & - & - & - & - \\
\hline Sweden & - & - & - & - & - & - & - & - & - & - & - & - & - \\
\hline United Kingdom & - & - & - & - & - & - & - & - & - & - & - & - & - \\
\hline Subtotal EU/EEA & 1,190 & 368 & $(30.9)$ & 198 & $(16.6)$ & 202 & $(17.0)$ & 157 & $(13.2)$ & 202 & $(17.0)$ & 63 & $(5.3)$ \\
\hline
\end{tabular}

EEA: European Economic Area; EU: European Union; MDR: multidrug-resistant; TOM: treatment outcome monitoring. 
among nationals was attributed to older age. These findings are not unexpected, and the similarities in terms of success rate, evident also at country level, seem to suggest that foreign-born patients are not at a higher risk of unfavourable outcome.

The analysis also revealed a potential for worsening of the $M / X D R$ TB epidemic in the EU and EEA, resulting from the high default rates recorded among retreatment and MDR TB cases $(14.8 \%$ and $13.2 \%$, respectively). Despite the data limitations with respect to the MDR TB analysis (with regards to data representativeness completeness and quality assurance of laboratory methods) a clear need for strengthening case holding and treatment monitoring among these two populations (retreatment and MDR TB) emerges. As widely shown in the literature, defaulting and previous unsuccessful treatment represent the biggest risk factor for the emergence of drug resistance, in particular M/XDR TB [15-18].

The role that surveillance of TB treatment outcomes can and ought to play in strengthening TB control needs to be highlighted. Reporting of outcomes allows close monitoring of the ability of TB programmes to support and ensure completion of patients' treatment. It also allows tailoring control activities to high-risk groups defined in terms of their inability to comply with treatment and achieve successful outcomes.

The claim that an unknown or unreported treatment outcome does not necessarily represent a negative one should be balanced against the argument that lack of knowledge about treatment outcomes deprives the programme of essential information to guide TB control.

Finally it should be noted that the importance of achieving the highest possible treatment success rate goes beyond its programmatic and epidemiological impact. Achieving universal success in treating individual patients remains a fundamental point in case management and patient care.

The importance of treatment outcome monitoring needs to be further stressed and mechanisms explored to maximise progress towards achievement of the targets. Clinicians, public health experts and policy makers must be convinced of the importance of a standardised approach to monitoring of treatment including a proper evaluation of its implementation. Only by recognising the key position that treatment outcome monitoring holds in TB control can progress towards elimination be pursued.

\section{Acknowledgements}

The authors would like to acknowledge the work of the ECDC national surveillance focal points who make EU/EEA TB surveillance possible. Finally a sincere acknowledgment and thanks to all clinicians that recognise the importance of treatment outcome monitoring and who make its reporting possible.
References

1. Global tuberculosis control: a short update to the 2009 report. Geneva: World Health Organization; 2009. Available from: http://www.who.int/tb/publications/global_report/2009/ update/tbu_9.pdf.

2. European Centre for Disease Prevention and Control/WHO Regional Office for Europe: Tuberculosis surveillance in Europe 2008. Stockholm, European Centre for Disease Prevention and Control, 2010. Available from: http://www.ecdc.europa. eu/en/publications/Publications/1003_SUR_tuberculosis_ surveillance_in_europe_2008.pdf

3. European Centre for Disease Prevention and Control. Annual Epidemiological Report on Communicable Diseases in Europe 2009. Stockholm, European Centre for Disease Prevention and Control.

4. Hollo V, Amato-Gauci A, Ködmön C, Manissero D. Tuberculosis in the EU and EEA/EFTA countries - what is the latest data telling us? Euro Surveill. 2009;14(11);pii=19151. Available from: http://www.eurosurveillance.org/ViewArticle. aspx?Articleld $=19151$

5. Fernandez de la Hoz K, Manissero D, on behalf of the Tuberculosis Disease Programme. A framework action plan to fight tuberculosis in the European Union. Euro Surveill.2008;13(12). pii=8074. Available from: http://www. eurosurveillance.org/ViewArticle.aspx?Articleld =8074

6. Dye C, Maher D, Weil D, Espinal M, Raviglione M. Targets for global tuberculosis control. Int J Tuberc Lung Dis. 2006;10(4):460-2.

7. MDG Monitor. Combat HIV/AIDS, Malaria and Other Diseases. United Nations Development Programme, 2007. Available from: http://www.mdgmonitor.org/goal6.cfm

8. The global plan to stop TB, 2006-2015 / Stop TB Partnership. Actions for life: towards a world free of tuberculosis. Geneva: World Health Organization; 2006. Available from: http://www. stoptb.org/globalplan/assets/documents/GlobalPlanFinal.pdf

9. Veen J, Raviglione M, Rieder HL, Migliori GB, Graf P, Grzemska $M$, et al. Standardized tuberculosis treatment outcome monitoring in Europe. Recommendations of a Working Group of the World Health Organization (WHO) and the European Region of the International Union Against Tuberculosis and Lung Disease (IUATLD) for uniform reporting by cohort analysis of treatment outcome in tuberculosis patients. Eur Respir J. 1998;12(2):505-10.

10. European Centre for Disease Prevention and Control/WHO Regional Office for Europe: Tuberculosis surveillance in Europe 2007. Stockholm, European Centre for Disease Prevention and Control, 2009. Available from: http://www.ecdc.europa. eu/en/publications/Publications/0904_SUR_Tuberculosis_ Surveillance_in_Europe.pdf

11. Smith I. What are the global targets for tuberculosis control, and what is the basis of these targets? Frieden T, editor. Toman's tuberculosis: case detection, treatment, and monitoring - questions and answers. 2nd ed. Geneva: World Health Organization; 2004.

12. Styblo K, Bumgarner R. Tuberculosis can be controlled with existing technologies:evidence. Tuberculosis Surveillance Research Unit. Progress Report, 1991. p:60-72.

13. Dye C, Garnett GP, Sleeman K, Williams BG. Prospects for worldwide tuberculosis control under the WHO DOTS strategy. Lancet. 1998;352(9144):1886-91.

14. Styblo K. Selected papers. Vol. 24. Epidemiology of tuberculosis. The Hague: Royal Netherlands Tuberculosis Association; 1991.

15. Manissero D, Fernandez de la Hoz K. Extensive drug-resistant TB: a threat for Europe? Euro Surveill. 2006;11(39). pii=3056. Available from: http://www.eurosurveillance.org/ViewArticle. aspx?Articleld $=3056$

16. Vashakidze L, Salakaia A, Shubladze N, Cynamon M, Barbakadze K, Kikvidze M, et al. Prevalence and risk factors for drug resistance among hospitalized tuberculosis patients in Georgia. Int J Tuberc Lung Dis. 2009;13(9):1148-53.

17. Faustini A, Hall AJ, Perucci CA. Risk factors for multidrug resistant tuberculosis in Europe: a systematic review. Thorax. 2006;61(2):158-63.

18. Faustini A, Hall AJ, Perucci CA. Tuberculosis treatment outcomes in Europe: a systematic review. Eur Respir J. 2005;26(3):503-10. 